\title{
Paulo Freire e Orlando Fals Borda na genealogia da pedagogia decolonial latino-americana
}

\author{
Paulo Freire y Orlando Fals Borda en la genealogía \\ de la pedagogía decolonial latinoamericana \\ Paulo Freire and Orlando Fals Borda in the Genealogy \\ of Latin American Decolonic Pedagogy
}

João Colares da Mota Neto ${ }^{1}$

\section{Resumo}

0 artigo tem por objetivo discutir as contribuições que os educadores populares Paulo Freire e Orlando Fals Borda forneceram, com suas obras e trajetórias político-intelectuais, para a formulação de uma pedagogia decolonial no continente latino-americano. A questão-chave que norteia este estudo é: qual o legado de Paulo Freire e Orlando Fals Borda para a constituição de uma pedagogia decolonial na América Latina? Os dados foram obtidos por meio de uma pesquisa de natureza teórica, inscrita nos domínios da história cultural e da história comparada do pensamento social latino-americano. As fontes primárias são as obras de Paulo Freire e Orlando Fals Borda, escritas em distintos momentos de suas trajetórias intelectuais. 0 artigo está organizado em duas partes centrais, além da introdução e das considerações finais: na primeira, de modo breve, apresenta-se a concepção de pedagogia decolonial adotada; na segunda, a partir desta concepção, perscruta-se o núcleo central das contribuições de Paulo Freire e Orlando Fals Borda para a formulação de uma pedagogia decolonial latino-americana.

\section{Palavras-chave}

Paulo Freire; Orlando Fals Borda; pedagogia decolonial; educação popular; América Latina

\section{Resumen}

El artículo tiene como objetivo discutir las contribuciones que los educadores populares Paulo Freire y Orlando Fals Borda proporcionaron, con sus obras y trayectorias políticas e intelectuales, a la formulación de una pedagogía decolonial en el continente latinoamericano. La cuestión fundamental que guía este estudio es: ¿cuál es el legado de Paulo Freire y Orlando Fals Borda para la constitución de una pedagogía decolonial en América Latina? Los datos fueron obtenidos a través de una investigación teórica, inscrita en los campos de la historia cultural y la historia comparativa del pensamiento social latinoamericano. Las fuentes primarias son las obras de Paulo Freire y Orlando Fals Borda, escritas en diferentes momentos de sus trayectorias intelectuales. El artículo se organiza en dos partes principales, además de la introducción y las consideraciones finales: en la primera, brevemente, se presenta la concepción de pedagogía decolonial adoptada; en la segunda, desde esta concepción, buscamos por el núcleo central de las contribuciones de Paulo Freire y Orlando Fals Borda a la formulación de una pedagogía decolonial latinoamericana.

\section{Palabras clave}

Paulo Freire; Orlando Fals Borda; pedagogía decolonial; educación popular; América Latina

1 Professor do Programa de Pós-Graduação em Educação e da Licenciatura em Pedagogia da Universidade do Estado do Pará (UEPA). Doutor em Educação pela Universidade Federal do Pará (UfPA), com Doutorado Sanduíche pela Universidad Pedagógica Nacional de Colombia (UPN). Correo electrónico: joacolares@hotmail.com 


\section{Abstract}

The paper aims to discuss the contributions that popular educators Paulo Freire and Orlando Fals Borda provided, through their work and their political and intellectual trajectories, to the formulation of a decolonial pedagogy in Latin America. The fundamental question guiding this study is: What is the legacy of Paulo Freire and Orlando Fals Borda for the constitution of a decolonial pedagogy in Latin America? The data was obtained through a theoretical investigation in the fields of cultural history and the comparative history of Latin American social thought. The primary sources are the works of Paulo Freire and Orlando Fals Borda, written at different times of their intellectual trajectories. The paper has two main parts other than the introduction and final considerations: in the first part, we briefly present the conception of decolonial pedagogy adopted; in the second part, and based on this conception, we look for the core of the contributions of Paulo Freire and Orlando Fals Borda to the formulation of a Latin American decolonial pedagogy.

\section{Keywords}

Paulo Freire; Orlando Fals Borda; decolonial pedagogy; popular education; Latin America

\section{Artículo recibido el 22 de febrero de 2017 y aprobado el 10 de enero de 2018}

\section{Introdução}

Neste artigo, temos por objetivo discutir as contribuições que os educadores populares Paulo Freire (1921-1997) e Orlando Fals Borda (19252008) forneceram, com suas obras e trajetórias político-intelectuais, para a formulação de uma pedagogia decolonial no continente latino-americano. A questão-chave que norteia este estudo é: qual o legado de Paulo Freire e Orlando Fals Borda para a constituição de uma pedagogia decolonial em nosso continente latino-americano?

As análises teóricas que conduzem este artigo são decorrentes de uma pesquisa de doutoramento em Educação já concluída, cujo objeto de estudo foi a constituição de uma concepção decolonial nas obras de Paulo Freire e Orlando Fals Borda, intelectuais reconhecidos nos campos da educação popular, da pedagogia crítica e das ciências sociais em nosso continente.

O estudo parte do reconhecimento de que tanto em Paulo Freire, o mais célebre pedagogo brasileiro, quanto em Orlando Fals Borda, o mais importante cientista social colombiano, encontramos conceitos, ideias, concepções e propostas metodológicas que nos permitem articular o referencial da educação popular com o da decolonialidade, buscando entender, a partir desse cruzamento, a constituição de um discurso pedagógico crítico das heranças do colonialismo nos territórios periferizados do Sul global, particularmente na América Latina.
Utilizamos o conceito de decolonialidade por inspiração de um conjunto de autores organizados em torno do "programa de investigação da modernidade/colonialidade latino-americano", ou, simplesmente, "rede modernidade/colonialidade", que reúne nomes como Enrique Dussel, Walter Mignolo, Aníbal Quijano, Catherine Walsh, Ramón Grosfoguel, Santiago Castro-Gómez, Edgardo Lander, Arturo Escobar, Nelson Maldonado-Torres, entre outros.

Decolonialidade, na esteira destes autores, designa o questionamento radical e a busca de superação das mais distintas formas de opressão perpetradas contra as classes e os grupos subalternos pelo conjunto de agentes, relações e mecanismos de controle, discriminação e negação da modernidade/ colonialidade. De outra forma, decolonialidade refere-se, segundo Walsh (2009), ao esforço por "transgredir, deslocar e incidir na negação ontológica, epistêmica e cosmogônico-espiritual que foi - e é - estratégia, fim e resultado do poder da colonialidade" (p. 27), o que significa, nas palavras de Walter Mignolo (2007), que a decolonialidade é uma "energía que no se deja manejar por la lógica de la colonialidad, no si cree los cuentos de hadas de la retórica de la modernidad" (p. 27).

O par modernidade/colonialidade, presente na escritura destes autores, deve-se à ênfase que querem dar à ideia de que a colonialidade é constitutiva e não derivativa da modernidade, que a colonialidade é o "lado obscuro" da modernidade, como gostam de 
afirmar, que o conceito emancipador hegemonicamente contido na ideia de modernidade é um mito porque não revela que ela só foi possível graças à opressão colonial que impôs aos povos conquistados da América Latina e de outros continentes. Daí que as instituições e os processos sociais atrelados ao fenômeno histórico da modernidade passam a ser questionados por estes autores por suas inter-relações (diretas ou indiretas, manifestadas ou ocultadas) na constituição da exclusão social, do racismo, da negação de direitos e de modos de ser.

Com efeito, para Mignolo (2007), a modernidade é uma hidra de três cabeças que simbolizam cada qual: i) a retórica salvacionista, desenvolvimentista e a promessa do progresso, esta que é a única face visível da modernidade; ii) a colonialidade, que é um padrão de poder que permaneceu mesmo após o fim da situação colonial e que entre suas consequências estão o racismo, a desigualdade, a fome e o machismo, formas de opressão que costumam estar deslocadas do imaginário hegemônico sobre a ideia de modernidade; iii) a decolonialidade, que é uma energia de descontentamento, de desconfiança, de desprendimento mobilizada por aqueles que reagem ante a violência imperial.

Com base nesta concepção, o argumento central que defendemos neste trabalho é o de que as obras de Paulo Freire e Orlando Fals Borda são um antecedente do debate da decolonialidade na América Latina e que a constituição de uma pedagogia decolonial em nosso continente se fortalece com as contribuições pedagógicas, políticas, epistemológicas e sociológicas que estes autores forneceram para a educação popular.

Desde nosso ponto de vista, este argumento pode ser sustentado com base nas trajetórias praxiológicas destes autores como intelectuais sentipensantes ${ }^{2} \mathrm{e}$ educadores terceiro-mundistas; em suas críticas

2 Este termo é do próprio Orlando Fals Borda (2003), para quem sentipensante é "aquella persona que trata de combinar la mente con el corazón, para guiar la vida por el buen sendero y aguantar sus muchos tropiezos" (p. 09). Trata-se, assim, de uma aposta na possibilidade de um outro perfil de educador, de investigador, de militante e de intelectual, em franca oposição à atitude fria e supostamente neutra do cientista positivista, tradicional e eurocêntrico. contundentes à natureza colonialista da sociedade, da pedagogia e da ciência dominante; em suas apostas rumo a uma educação popular dialógica, intercultural, conscientizadora e pesquisadora; bem como em suas utopias rebeldes, subversoras e insurgentes.

Especificamente neste trabalho, por necessidade de delimitação, abordaremos os traços que consideramos mais centrais da convergência de pensamentos dos dois autores em análise, tendo em vista a formulação de uma pedagogia decolonial na América Latina. Deste modo, pretendemos colocar os dois intelectuais em perspectiva, efetivando uma espécie de comparação entendida como um recurso dialógico de construção de uma intertextualidade.

Os dados do estudo foram obtidos a partir de uma pesquisa de natureza teórica, com enfoque metodológico inscrito nos domínios da história cultural e da história comparada do pensamento social, considerando-se que ambas oferecem formas de problematização da cultura - em sentido ampliado, no interior da qual se localizam as produções intelectuais - que permitem articular texto e contexto, indivíduo e história, local e global. Quanto às fontes utilizadas neste estudo, as obras de Paulo Freire e de Orlando Fals Borda, escritas em distintos momentos de sua trajetória intelectual, são as primárias, e os demais materiais bibliográficos podem ser considerados como fontes secundárias.

Além desta introdução e das considerações finais, o artigo está organizado em duas partes centrais: na primeira, de modo mais breve, apresentamos nossa concepção de pedagogia decolonial, em diálogo com autores de referência no assunto; na segunda parte, procuramos extrair o núcleo central das contribuições de Paulo Freire e Orlando Fals Borda para a formulação de uma pedagogia decolonial latino-americana.

\section{Concepção de pedagogia decolonial}

$\mathrm{O}$ que vem a ser uma pedagogia decolonial? Quais os seus traços marcantes? Como ela se vincula aos pensamentos e às lutas decoloniais? Se o pensamento decolonial denota as práticas epistêmicas de 
reconhecimento e transgressão da colonialidade, que se produziram na América Latina e em outras regiões colonizadas como respostas à situação de dominação, podemos dizer que a pedagogia decolonial refere-se às teorias-práticas de formação humana que capacitam os grupos subalternos para a luta contra a lógica opressiva da modernidade/colonialidade, tendo como horizonte a formação de um ser humano e de uma sociedade livres, amorosos, justos e solidários (Mota Neto, 2016).

Para Walsh (2013), neste sentido, o enlace do decolonial com o pedagógico começa com a invasão colonial-imperial e as resistências a ela. A pedagogia, portanto, deve ser vista no contexto das lutas decoloniais, que pretendem a viabilização da humanidade contra a matriz colonial e seu padrão de racialização-desumanização que há mais de 500 anos vêm oprimindo e vitimando homens e mulheres.

Ainda de acordo com esta autora, a decolonialidade não é uma teoria a ser seguida, mas um projeto por assumir, "Es un proceso accional para pedagógicamente andar" (p. 67). Em outro texto, ela definiu as pedagogias decoloniais como ações que promovem e provocam fissuras da ordem moderno/colonial, as quais tornam possível e dão sustento e força a um modo distinto, inteiramente outro, de estar no e com o mundo (Walsh, 2014).

Para Díaz (2010), por sua vez, uma pedagogia decolonial assume como horizonte de trabalho as categorias propostas pelo "giro decolonial", seus significados e propósitos, mas de uma maneira que o pedagógico seja o eixo, o horizonte e o dispositivo para sua concretização.

Neste sentido, as pedagogias decoloniais estimulam o pensar a partir de genealogias, racionalidades, conhecimentos, práticas e sistemas civilizatórios e de vida distintos. São pedagogias que incitam possibilidades de estar, ser, sentir, existir, fazer, pensar, olhar, escutar e saber de outro modo, pedagogias encaminhadas em direção a processos e projetos de caráter, horizonte e intenção decoloniais (Walsh, 2013).

A autora afirma que esta concepção se alia à chamada pedagogia crítica iniciada por Paulo Freire nos anos 1960 e retomada por muitos educadores populares e ativistas-intelectuais ao redor do mundo até os anos 1990, quando começa a enfraquecer devido ao auge do projeto neoliberal e à dissipação da utopia revolucionária marxista, no contexto da queda do muro de Berlim e da fragmentação da União Soviética (Walsh, 2013).

No entanto, também nos anos 90, emerge com força os movimentos indígenas no continente latino-americano, renomeado como Abya Yala ${ }^{3}$. Deste momento em diante, a luta por transformação é redirecionada e ressignificada. Afirma Walsh (2013) que já não está em pauta apenas a questão social, ligada à equidade e à eliminação da desigualdade, mas também as questões étnicorraciais assumem lugar de destaque e dão novos contornos e propósitos à pedagogia, hoje também chamada de decolonial.

Tendo por base esta concepção de pedagogia decolonial, como podemos percebê-la no seio da educação popular latino-americana? Como Freire e Fals Borda se articulam e contribuem para a construção deste projeto a partir da educação popular? Quais os elementos de convergência, presentes no ideário sociopedagógico dos dois autores, que se entrelaçam com a concepção pedagógica decolonial? São questões que discutiremos a seguir.

\section{A pedagogia decolonial como expressão da educação popular latino-americana}

Paulo Freire e Orlando Fals Borda, inscritos no movimento da educação popular latino-americana, são referências intelectuais e políticas deste projeto de afirmação de uma pedagogia decolonial. Eles fornecem elementos fundamentais para a articulação entre o pedagógico e o decolonial, isso é, tanto para pensar pedagogicamente a decolonialidade quanto para refletir, em termos decoloniais, sobre a pedagogia.

3 Abya Ayla é o nome com que os indígenas Kuna, do Panamá e da Colômbia, chamavam o continente americano antes da Conquista espanhola. Significa "terra de plena maturidade" ou "terra de sangue vital". 
Procuraremos explorar esta afirmação sustentando que em Freire e Fals Borda a concepção de pedagogia decolonial: a) requer educadores subversivos; b) parte de uma hipótese de contexto; c) valoriza as memórias coletivas dos movimentos de resistência; d) está em busca de outras coordenadas epistemológicas; e) afirma-se como uma utopia política.

\section{a) Pedagogia que requer educadores subversivos}

Tanto em Freire quanto em Fals Borda encontramos a ideia de que não é possível apartar a subjetividade, da objetividade; o criador, da criatura; o educador, da educação; o indivíduo, da sociedade. Ou seja, não se pode construir uma pedagogia decolonial com educadores que atuem de modo a reproduzir o modus operandi da opressão. Afinal, o colonialismo não se expressa apenas no plano do pensamento, mas também no das práticas e das relações sociais.

Portanto, uma pedagogia decolonial requer educadores subversivos, no sentido falsbordiano de que a subversão está ligada, teleologicamente, a um projeto de reconstrução da sociedade (Fals Borda, 2008 [1967]). Requer, em termos freireanos, educadores progressistas, democráticos, críticos, que desenvolvam estratégias de trabalho que possibilitem aos oprimidos revelarem sua situação de opressão e se engajarem na luta por sua transformação (Freire, 1987).

Freire e Fals Borda, seja em seus escritos, seja em suas trajetórias, delineiam o perfil de um educador decolonial. Trata-se de alguém comprometido politicamente com as classes populares e os grupos oprimidos; com sensibilidade ética para lidar com a dor e o sofrimento do outro; que tenha capacidade de liderança democrática, impulsionando projetos coletivos e sendo guiado por eles; com humildade e fé na capacidade das pessoas mais sofridas; que possua respeito pelos saberes populares e conhecimentos ancestrais, embora sem ser populista; que desenvolva capacidade de trânsito em distintos espaços sociais, sabendo que seu lugar prioritário é ao lado dos movimentos de resistência; que seja autêntico nas suas relações com as camadas populares, ou seja, que demonstre seu compromisso orgânico, mas sem pretender se confundir com elas.

Consideramos plausível, por isso mesmo, definir estes autores como educadores do Terceiro Mundo e intelectuais sentipensantes. Com efeito, ambos posicionaram-se ao lado dos condenados da terra dos países periféricos do Sul global, combinando razão crítica, emoção, compromisso e fé.

Este vínculo orgânico e participativo com os subalternos, que é uma característica do educador decolonial subversivo, requer, também, que ele desenvolva sua pedagogia a partir das fissuras ou das feridas abertas pela colonialidade/modernidade, isto é, que ele seja um testemunho crítico da opressão e um transgressor das relações de dominação, junto com os outros oprimidos. Por isso, não cabe a arrogância, o elitismo e o academicismo tão presentes nos educadores bancários tradicionais, devendo-se abrir espaço para um diálogo franco e construtivo com as bases, como o fizeram em vida e obra Freire e Fals Borda.

Freire, neste sentido, construiu os primeiros traços de sua pedagogia junto aos famintos e aos pobres do Nordeste brasileiro. Mas os oprimidos com os quais dialogou ao longo de sua trajetória sentipensante, ao redor de todo o mundo, incluem os trabalhadores rurais sem terra e os operários da construção civil do Brasil, os camponeses chilenos, as mulheres de cor e os negros dos guetos estadunidenses, os imigrantes na Europa, os revolucionários sandinistas da Nicarágua, os africanos em luta independentista, dentre muitos outros. Fals Borda, também, construiu a investigação-ação participativa (IAP) e a educação popular na Colômbia em íntimo diálogo com os campesinos andinos e costeños, os negros dos palenques ${ }^{4}$ e os indígenas da Amazônia colombiana.

O educador decolonial, por isso mesmo, enfrenta junto com os oprimidos os seus desafios e suas situações-limites. É neste sentido que Freire e Fals Borda não só apoiaram intelectualmente a diversos movimentos de resistência e processos revolucionários,

40 equivalente colombiano dos quilombos brasileiros. 
como se engajaram concretamente neles. Vale lembrar que ambos estiveram juntos na Revolução Sandinista e na África pós-colonial, contribuindo, a partir da educação popular e da IAP, para a luta revolucionária. Ambos estiveram envolvidos, também, na construção de partidos políticos democráticos, assumindo com radicalidade a natureza política da educação popular e da pesquisa social.

Mas, com capacidade de trânsito, ambos se movem entre a política, a luta revolucionária, os movimentos sociais, a academia, o governo e as organizações não governamentais, o que fornece uma feição fronteiriça ao perfil de educador decolonial que estamos aqui desenvolvendo. $\mathrm{Na}$ realidade, não se trata apenas de viver na fronteira ou de pensar a partir dela, mas de ser politicamente estratégico, lendo o contexto e verificando em quais espaços sua atuação poderia surtir os melhores efeitos.

\section{b) Pedagogia que parte de uma hipótese de contexto}

Outro legado de Freire e Fals Borda para a pedagogia decolonial é o ensinamento de que a educação, para ter sentido e ser efetiva, precisa estar "organicamente" ligada às situações de vida dos grupos oprimidos e à sua realidade regional, nacional e transnacional.

Orlando Fals Borda chamou de hipótese de contexto para a necessidade de adequação dos marcos de referência científicos aos contextos geográficos, culturais e históricos concretos, caso efetivamente se queira enfrentar o colonialismo intelectual e construir uma ciência própria latino-americana (Fals Borda \& Mora-Osejo, 2007).

Paulo Freire (2003, 2008, 1987), no mesmo sentido, desde os seus primeiros escritos, foi crítico do mimetismo intelectual e das "receitas prontas" vindas de contextos exógenos à realidade local dos trabalhos de educação popular. Dizia que para que seja transformadora, a educação deve estar ligada aos interesses das camadas populares, superando a invasão cultural que há séculos tem servido como instrumento de dominação dos opressores sobre os oprimidos.
Uma pedagogia decolonial, em nosso entendimento, deve partir desta hipótese de contexto que está presente nas ideias tanto de Freire quanto de Fals Borda. Ora, não é possível enfrentar a invasão cultural, a colonialidade e o colonialismo intelectual e pedagógico se não aprendermos a estabelecer outra relação com o saber local, com as histórias de vida dos educandos, com as necessidades concretas dos movimentos sociais, com os desejos e os medos das classes populares.

Desse modo, a educação popular, ao enfrentar essa racionalidade estreita, totalitária, propondo o que Fals Borda (2010 [2005]) chamou de diálogo de saberes e Freire (1987) de síntese cultural, contribui para a consolidação de uma pedagogia decolonial em nosso continente, valorizando as culturas populares, as memórias e os saberes das classes populares.

A partir da leitura dos dois autores, entendemos que o reconhecimento do contexto concreto e a valorização dos saberes culturais se dão a partir de dois mecanismos: por um lado, por meio da pesquisa, que Fals Borda (1985) chamou de investigação-ação participativa (IAP) e Freire (1987) de pesquisa do universo temático; por outro, através do diálogo profundo, construtivo e permanente com as camadas populares, em todos os momentos do processo educativo.

Há uma série de convergências entre as duas concepções de pesquisa. Em primeiro lugar, ambas estão ligadas a uma intencionalidade transformadora. Não são apenas um recurso de "descoberta" da realidade, mas uma estratégia de leitura crítica do mundo e conscientização dos grupos oprimidos para a mudança social. Em segundo lugar, tanto a IAP quanto a pesquisa do universo temático (ou investigação dos temas geradores) superam a dicotomia sujeito-objeto, típica das pesquisas tradicionais. Em terceiro lugar, consequentemente, a investigação assume um caráter dialógico e participativo, sendo as classes populares protagonistas da investigação/ educação/mudança social.

A defesa da dimensão educativa da investigação e do componente investigativo intrínseco da educação, feita por Freire e Fals Borda, dá materialidade a esta pedagogia decolonial que busca partir de 
uma hipótese de contexto. Fals Borda (2010 [1995]) chamou de educação popular pesquisadora e participante para esta busca de convergência entre o legado da IAP e o da educação freireana. Educação fundada nas categorias participação, práxis, diálogo, conscientização, que certamente dão substância e formato a uma pedagogia rebelde, subversiva, insurgente...decolonial!

\section{c) Pedagogia que valoriza as memórias coletivas dos movimentos de resistência}

Procedimento de fundamental importância para a pedagogia decolonial, e que constitui parte do legado intelectual de Paulo Freire e Orlando Fals Borda, é a valorização das memórias coletivas dos movimentos de resistência. Estes movimentos, há mais de 500 anos, têm resistido à dominação colonial, imperial, capitalista, armazenando em seus acervos seculares (e até milenares) de conhecimento uma série de estratégias de sobrevivência e enfrentamento da opressão.

São conhecimentos que, apesar do epistemicídio promovido pela modernidade/colonialidade, teimam em resistir, e são repassados de geração a geração por meio de práticas formativas muito peculiares, que infelizmente a ciência pedagógica, de dominância positivista e eurocêntrica, tem ignorado.

Mas qual a importância da memória coletiva e como isso articula Freire, Fals Borda e a decolonialidade? Para Walsh (2013), a memória coletiva tem sido o espaço onde se relaciona, na prática mesma, o pedagógico e o decolonial. Por isso, a autora nos diz que a pedagogia decolonial está relacionada às memórias que os povos indígenas e afrodescendentes, por exemplo, vieram mantendo como parte de sua existência e de sua luta. Para ela, a memória coletiva articula a continuidade de uma aposta decolonial, é como "este vivir de luz y libertad en medio de las tinieblas" (p. 26).

Para Marín (2013), os projetos e as práticas no campo da memória podem ser concebidos no interior do horizonte da decolonialidade, por dois motivos: primeiro, pela visibilização de epistemes que foram subalternizadas pela lógica do poder colonial e pela colonialidade; segundo, porque mobilizam dinâmicas de transformação dos legados coloniais que ainda hoje persistem.

Ainda de acordo com Marín (2013), a recuperação coletiva, segundo Fals Borda e Freire, nos mostrou a possibilidade de produzir conhecimento a partir da práxis política e ética, assim como a partir das diversas lógicas de saber no interior dos setores populares. Em consequência, começou-se a produzir "outras" narrativas históricas, que assumiram forma dissidente em relação às oficiais, apontando para um conhecimento produzido no seio do movimento popular.

Com efeito, compõe a proposta da IAP o que Fals Borda (1985) chamou de recuperação coletiva da história, que visa a recontar a história a partir do ponto de vista dos "oprimidos", das classes populares, dos campesinos, dos indígenas, dos negros, dando visibilidade a seus heróis, a suas lutas, a suas tradições artísticas, a suas memórias, em geral silenciadas ou deturpadas pela história oficial.

Esta recuperação, na concepção falsbordiana, deve ser feita pelas próprias classes populares, com a ajuda dos intelectuais orgânicos, que contribuem pela restituição sistemática ou para a popularização de técnicas de pesquisa científica, tornando a investigação um procedimento dialógico e conscientizador. É assim que a proposta de Fals Borda se soma ao pensamento de Paulo Freire, que também forneceu contribuições neste sentido da recuperação coletiva, quando, por exemplo, defendeu a investigação do universo temático, a seleção dos temas e das palavras geradoras, o diálogo com as comunidades populares, a valorização do saber de experiência feito, o protagonismo das classes populares na construção do conhecimento e a síntese cultural entre o saber popular e o saber científico (Freire, 1987).

A construção de uma ciência popular, fecundada no diálogo entre saberes, na recuperação coletiva da história e na intencionalidade transformadora e educativa de todo e qualquer procedimento de construção do conhecimento apresenta-se, em nossa visão, como um fundamento de uma pedagogia decolonial latino-americana e uma lição ensinada por Freire e Fals Borda para o movimento da 
educação popular e para as ciências sociais críticas em nosso continente.

\section{d) Pedagogia em busca de outras coordenadas epistemológicas}

Freire e Fals Borda construíram contundentes críticas ao colonialismo e à colonialidade também no plano do pensamento científico e filosófico. Fals Borda (1970), desde o início dos anos 70, quando publica Ciencia Propia y Colonialismo Intelectual, denunciou o colonialismo intelectual e o eurocentrismo que, reproduzido nas academias de toda a América Latina, reforçam o silenciamento de nossa realidade e inferiorizam nossos quadros intelectuais. Freire (2003), já na sua tese elaborada para ingresso na cadeira de História e Filosofia da Educação da então Universidade do Recife, critica, junto ao aspecto epistemológico, a força do colonialismo que se faz presente no patriarcado, no racismo, no latifúndio, na invasão cultural, na cultura do silêncio, na violência, no mutismo, na passividade, no assistencialismo.

Ambos estavam muito conscientes das relações intrínsecas entre colonialismo intelectual, capitalismo, racismo, patriarcado e imperialismo, propondo repensar a pedagogia e as ciências sociais - consequentemente a educação popular - a partir de bases não eurocêntricas, mas endogenéticas, nos termos de Fals Borda (2007). Em suma, defenderam a nossa autonomia intelectual e o nosso direito à autodeterminação, isto é, a possibilidade de os povos do Sul trilharem o seu próprio caminho, o que Freire (2014) chamou de sulear.

Evidentemente que esta posição intelectual é reforçada pela estrutura de sentimentos (Williams, 1997 [1975]) da época. A segunda metade do século xx é marcada, na obra de um conjunto crescente de intelectuais críticos, por um terceiro-mundismo ou latino-americanismo que encontra expressão na sociologia, pedagogia, filosofia, teologia, não à toa identificadas como sendo da libertação.

Isto não representou um fechamento em relação aos ensinamentos de tradições críticas vindas da Europa ou dos Estados Unidos. Afinal, tanto Freire quanto Fals Borda viveram nestes locais e construí- ram relações com intelectuais e movimentos aliados. Mas, sem negar o diálogo, este terceiro-mundismo significou uma busca por novas coordenadas epistemológicas, mais autônomas, que representassem melhor o ponto de vista das camadas populares do Sul global.

Isto explica a maneira não ortodoxa com que Freire e Fals Borda incorporaram, por exemplo, o marxismo. Negando o economicismo e o estruturalismo muito evidentes em parte do marxismo latino-americano, que, diga-se de passagem, não raro foi uma reprodução eurocêntrica do marxismo pensado em outras latitudes, estes educadores foram capazes de introduzir a cultura quando só havia economia, o ser humano quando só as estruturas "falavam", a emoção quando só havia espaço para a fria razão, a religião quando esta era apenas o "ópio do povo".

Entendemos que isto não se deve apenas à influência, de fato importante, de Antonio Gramsci, mas também de outros personagens da periferia mundial, que heterodoxamente releram o marxismo ocidental, como Amílcar Cabral, Frantz Fanon, Camilo Torres e Che Guevara. De igual forma, deve-se à influência sobre Freire e Fals Borda de tradições de pensamento latino-americanas que cruzaram o marxismo com outras correntes filosóficas, como a teologia da libertação, que aproximou Marx ao humanismo cristão.

Além da teologia da libertação e da releitura do marxismo, Freire e Fals Borda também buscaram outras coordenadas epistemológicas dialogando com perspectivas teóricas emergentes no final do século $\mathrm{xx}$, como a pós-modernidade de oposição e o multiculturalismo e, no caso de Fals Borda, também com a teoria pós-colonial e os estudos culturais.

Isto não significou, em nenhuma hipótese, o abandono dos marcos de referência anteriores, mas uma atualização e ampliação do seu discurso teórico. Nesta busca por outras coordenadas epistemológicas, está muito evidente em ambos os autores o enfrentamento de binarismos clássicos do pensamento moderno, como objetividade $\mathrm{x}$ subjetividade, razão $\mathrm{x}$ emoção, indivíduo $\mathrm{x}$ sociedade, cultura $\mathrm{x}$ economia, psicologia $\mathrm{x}$ sociologia, macropolítica $\mathrm{x}$ micropolítica, fé $\mathrm{x}$ ciência, ensino $\mathrm{x}$ aprendizagem, 
pesquisador $\mathrm{x}$ comunidades, liderança $\mathrm{x}$ povo, cultura erudita $\mathrm{x}$ cultura popular, local $\mathrm{x}$ global.

E, ao buscar a superação destas dicotomias, verificamos neles a valorização daquilo que Fals Borda (2010 [1986]) chamou de racionalidade do cotidiano, e a necessidade de se fazer ciência a partir desta racionalidade. Ou seja, suas propostas combinavam o vivencial com o racional, subvertendo a lógica hierarquizadora e dicotômica da ciência moderna.

Entendemos que a construção de uma pedagogia decolonial requer a transgressão da ciência moderna e uma busca de outras coordenadas epistemológicas. Assim como Freire (1978) falou em "descolonizar as mentes" e em "reafricanizar as mentalidades", defendemos que uma pedagogia decolonial, em nosso continente, deve "latino-americanizar as mentalidades", e nisto Freire e Fals Borda contribuíram significativamente.

\section{e) Pedagogia como utopia política}

Freire e Fals Borda contribuem para uma pedagogia decolonial na América Latina por terem introduzido, sem vieses positivistas, a política na educação. Apontaram para o caráter eminentemente político de todo e qualquer processo de formação humana e, dialeticamente, enfatizaram o aspecto pedagógico da luta política. Enfrentando as abordagens crítico-reprodutivistas, sobretudo de matriz francesa, fortes na academia latino-americana dos anos 1970, que enfatizavam o papel da escola na reprodução da desigualdade social, mas quase sem oferecer perspectivas de mudança, ambos os autores destacaram a força do sujeito e dos movimentos organizados na luta pela transformação da sociedade e o papel da educação neste processo.

A dialética denúncia-anúncio é estruturante da concepção pedagógica e sociológica destes autores, o que significa dizer que junto com a crítica radical e contundente da opressão, eles apresentaram caminhos, propostas, projetos de mudança social, movidos pela utopia de um mundo mais solidário, batizado como socialismo raizal, autóctone ou radical, na linguagem de Fals Borda (2007), de socialismo democrático, em Freire (2000), ou de democracia participativa, em ambos.

Sem otimismo ingênuo, e nem pessimismo amedrontador, Freire e Fals Borda interpretaram crítica e metodicamente a realidade em que viviam, denunciaram as estruturas de opressão, vislumbraram um mundo mais solidário e livre da desigualdade, da violência e do preconceito, construíram ferramentas científicas e pedagógicas para esta busca e se engajaram individual e coletivamente em projetos de transformação radical e estrutural da sociedade.

Dizemos "transformação radical e estrutural" porque ambos estavam convencidos de que a opressão sobre as classes populares não envolve apenas uma dimensão da realidade, a econômica, por exemplo. A opressão, que vem se construindo em nosso continente desde a Conquista, espraia-se para as esferas culturais, sociais, mentais, educacionais, produzindo a vítima não só pelas relações de exploração no trabalho, mas também pelo racismo, pelo machismo, pela discriminação linguística e muitas outras formas.

Por isso, apenas uma revolução, ou uma transformação profunda da sociedade, que implicasse em mudanças em todas essas esferas sociais, poderia dar respostas adequadas aos reclamos das classes oprimidas. Na África, Freire (2000) chegou a propor uma ruptura radical com o colonialismo e o neocolonialismo. Com a mesma coragem, Fals Borda (2007) propunha o "renascimento" ou o "despertar" da Colômbia, sintetizado na expressão indígena Kaziyadu.

A transformação, por isso, exigia bem mais que a mera tomada do poder, que deveria, mais propriamente, ser reinventado, como gostava de dizer Freire (2000). Em Fals Borda (2007), também, o poder não se concentrava apenas no Estado, embora esta fosse uma frente fundamental de luta. O poder era visto como uma malha de relações e que envolvia o conjunto da sociedade, das instituições, das práticas e das relações sociais.

O projeto socialista que defenderam, associado à IAP e à educação popular, caminha em direção contrária ao que Freire (1982) chamou de colonialismo 
revolucionário, quer dizer, não é um socialismo a ser decretado pelas vanguardas, mas construído, no cotidiano, pelas classes populares, recuperando o que Fals Borda (2007) denominou origens telúricas e fontes históricas, isso é, os valores fundantes de nossas populações ancestrais latino-americanas.

\section{Considerações finais}

A análise que realizamos das obras de Paulo Freire e Orlando Fals Borda nos permitem concluir que suas contribuições intelectuais devem estar inscritas na genealogia do pensamento decolonial, uma vez que, a partir da pedagogia e da pesquisa social, forneceram elementos fundamentais para não só questionar a vigência da colonialidade nos planos do existir, do poder e do pensar, mas também porque construíram estratégias de formação-militância-investigação profundamente descolonizadoras e emancipadoras.

Entendemos também que a educação popular, como movimento e como discurso no interior do pensamento crítico decolonial, inspirada nos dois autores aqui analisados, tem contribuído e pode continuar aportando: a) para a defesa da unidade latino-americana contra o imperialismo e as relações neocoloniais promovidas pelo capitalismo; b) para a produção de um pensar pedagógico que rompa com a subalternização dos conhecimentos e das experiências de sujeitos sociais marginalizados; c) para as lutas sociais de campesinos, trabalhadores urbanos, negros, índios, homossexuais, mulheres, jovens, refugiados, imigrantes, entre outros; d) para a construção de metodologias e propostas didáticas que viabilizem a participação e a construção do conhecimento destes sujeitos.

Entendemos, também, que explorar o aspecto decolonial em ambos os autores é um esforço de valorização dos pensamentos de Freire e Fals Borda, abordando uma temática ainda pouco trabalhada por seus estudiosos; uma tentativa de contribuir para o movimento da educação popular na América Latina, analisando suas contribuições para a formulação de uma pedagogia emancipatória, crítica e decolonial em nosso continente; uma aposta na possível contribuição deste estudo para o debate da decolonialidade, aproximando o pedagógico do decolonial.

Consideramos, a par da análise feita neste trabalho, que é urgente que sigamos avançando na construção de práticas, conceitos e linguagens que fortaleçam uma pedagogia decolonial em nosso continente, ligada a um projeto de emancipação que garanta o direito de todos à existência, ao trabalho, à liberdade, à justiça e à educação. As biobibliografias de Paulo Freire e Orlando Fals Borda nos são inspiradoras para esta caminhada.

\section{Referências}

Díaz, C. (2010). Hacia una pedagogía en clave decolonial: entre aperturas, búsquedas y posibilidades. Tabula Rasa, 13, 217-233.

Fals Borda, O. (1970). Ciencia Propia y Colonialismo Intelectual. Ciudad de México: Editorial Nuestro Tiempo.

Fals Borda, O. (1985). Conocimiento y poder popular: Lecciones con campesinos de Nicaragua, México, Colombia. Bogotá: Punta de Lanza; Siglo xxi Editores.

Fals Borda, O. (2003). Ante la crisis del país: ideasacción para el cambio. Bogotá: El Áncora Editores; Panamericana Editorial.

Fals Borda, O. (2007). Socialismo raizal y el ordenamiento territorial. Bogotá: Ediciones Desde Abajo.

Fals Borda, O. (2008 [1967]). La subversión en Colombia: el cambio social en la historia. 4a. ed. Bogotá: FICA-CEPA.

Fals Borda, O. (2010 [2005]). Da pedagogia do oprimido à pesquisa participativa. Em D. Streck (ed.), Fontes da Pedagogia Latino-Americana: uma antologia. Belo Horizonte: Autêntica Editora.

Fals Borda, O. (2010 [1995]). Pesquisa-Ação, ciência e educação popular nos anos 90. Em D. Streck (ed.), Fontes da Pedagogia Latino-Americana: uma antologia. Belo Horizonte: Autêntica Editora.

Fals Borda, O. (2010 [1986]). La investigación-acción participativa: política y epistemología. En J.M. Guerra (ed.), Antología Orlando Fals Borda. Bogotá: Universidad Nacional de Colombia.

Fals Borda, O. y Mora-Osejo, L. (2007). La superación del eurocentrismo: Enriquecimiento del saber sistémico y endógeno sobre nuestro contexto tropical. 
Aquelarre - Revista del Centro Cultural Universitario, 6(11), 115-124.

Freire, P. (1978) Cartas à Guiné Bissau: registros de uma experiência em processo. 4a. ed. Rio de Janeiro: Paz e Terra.

Freire, P. (1982). Ação cultural para a liberdade e outros escritos. 6a. ed. Rio de Janeiro: Paz e Terra.

Freire, P. (1987). Pedagogia do Oprimido. 29a. ed. Rio de Janeiro: Paz e Terra.

Freire, P. (1999). Criando métodos de pesquisa alternativa: aprendendo a fazê-la melhor através da ação. Em C.R. Brandão (Ed.), Pesquisa Participante. 8a. ed. São Paulo: Brasiliense.

Freire, P. (2000). Pedagogia da Esperança: Um reencontro com a Pedagogia do oprimido. (7ed). São Paulo: Paz e Terra.

Freire, P. (2003). Educação e Atualidade Brasileira. 3a. ed. São Paulo: Cortez; Instituto Paulo Freire.

Freire, P. (2008). Educação como Prática da Liberdade. 31a. ed. Rio de Janeiro: Paz e Terra.

Freire, P. (2014). Pedagogia dos sonhos possíveis. São Paulo: Paz e Terra.

Marín, P. (2013). Memoria Colectiva: Hacia un proyecto decolonial. In C. Walsh (ed.), Pedagogías decoloniales: Prácticas insurgentes de resistir, (re)existir y (re)vivir. Quito: Ediciones Abya-Yala.
Mota Neto, J. (2016). Por uma Pedagogia Decolonial na América Latina: reflexões em torno do pensamento de Paulo Freire e Orlando Fals Borda. Curitiba: CRV.

Mignolo, W. (2007). El Pensamiento Decolonial: Desprendimiento y Apertura. Un manifesto. In S. Castro-Gómez \& R. Grosfoguel (Ed.), El Giro Decolonial: Reflexiones para una diversidad epistémica más allá del capitalismo global. Bogotá: Siglo del Hombre Editores; Universidad Central, Instituto de Estudios Sociales Contemporáneos, Pontificia Universidad Javeriana, Instituto Pensar.

Walsh, C. (2009). Interculturalidade, crítica e pedagogia decolonial: in-surgir, re-existir e re-viver. Em V.M. Candau (ed.), Educação intercultural na América Latina: entre concepções, tensões e propostas. Rio de Janeiro: 7Letras.

Walsh, C. (2013). Lo pedagógico y lo decolonial: Entretejiendo caminos. En C. Walsh (ed.), Pedagogías decoloniales: Prácticas insurgentes de resistir, (re) existir y (re)vivir. Quito: Ediciones Abya-Yala.

Walsh, C. (2014). Pedagogías decoloniales caminando y preguntando. Notas a Paulo Freire desde Abya Yala. Revista Entramados - Educación y Sociedad, 1, 17-31.

Williams, R. (1997 [1975]). Você é marxista, não é? Praga - Revista de Estudos Marxistas, 2, 123-133. 